\title{
Surgical and postsurgical wound care in hidradenitis suppurativa
}

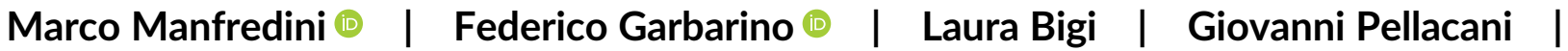 Cristina Magnoni}

Section of Dermatology, Department of Surgical, Medical, Dental and Morphological Sciences With Interest Transplant, Oncological and Regenerative Medicine, University of Modena and Reggio Emilia, Modena, Italy

\section{Correspondence}

Cristina Magnoni, Section of Dermatology, Department of Surgical, Medical, Dental and Morphological Sciences With Interest Transplant, Oncological and Regenerative Medicine, University of Modena and Reggio Emilia, via del Pozzo n.71, Modena 41124, Italy.

Email: magnoni.cristina@gmail.com

\begin{abstract}
Hidradenitis suppurativa (HS) is a chronic inflammatory disorder. Several medical treatments, with varying degree of efficacy, have been developed. However, in most cases of advanced (HS), the definitive treatment option is often represented by surgical excisions. Surgical techniques, reconstructive approach, and local wound care should be accurately designed in order to obtain the best result. In this letter, we analyzed the possible surgical treatments and local wound care. A literature review was performed on the various surgical treatments, reconstructive techniques, and local wound care. Surgical treatment is a common therapeutic modality for HS. Different surgical reconstructive techniques and postsurgical wound care approaches are described for the management of HS patients. There were few high-quality evidence-based studies evaluating the surgical management of HS. Many disparate HS severity scores were used in these studies making comparison between them difficult. Nonetheless, research into different surgical approaches and wound care management has increased substantially in the past decade and has given patients more surgical therapeutic strategies. The description of the best combinations and timing of surgery, wound care and medical therapies, will be a matter of future research for the definition of the optimal management of HS patient.
\end{abstract}

\section{KEYWORDS}

hidradenitis suppurativa, surgery, wound care

\section{1 | INTRODUCTION}

Multiple treatments have been described for the management of HS patients (Alikhan et al., 2019a; 2019b; Bettoli, Manfredini, Calamo, et al., 2018; Bettoli, Manfredini, Massoli, et al., 2018). Surgical approaches are a quite common therapeutic modality for severe HS, even though postsurgical management is usually more complex with respect to other because of the large areas involved and of the ongoing inflammatory process in the adjacent involved skin areas (Garbarino, Manfredini, Rossi, \& Magnoni, 2019).

\section{2 | SURGICAL APPROACHES}

The choice of the surgical procedure is strictly dependent on patients' characteristics, body location and disease severity. Incision and drainage are the easiest procedures providing short-term benefits and temporary pain relief. Deroofing implies the removal of the sinus "roof" electrosurgically. Adjunctive therapies, such as cryoinsufflation, laser and light-based therapies, have become more commonly used in the management of $\mathrm{HS}$ and are used for specific purposes, such as: targeting the hair follicle, reducing the bacterial load, and for tissue debulking (Alikhan et al., 2019b). 
TABLE 1 Reconstructive techniques and postsurgical wound care

\begin{tabular}{|c|c|}
\hline \multicolumn{2}{|c|}{ Reconstructive techniques } \\
\hline $\begin{array}{l}\text { Secondary } \\
\text { intention } \\
\text { healing }\end{array}$ & $\begin{array}{l}\text { Secondary intention healing (SIH) is the most } \\
\text { elemental form of wound closure and the } \\
\text { most basic technique in the reconstructive } \\
\text { ladder. This approach may be successful both } \\
\text { in narrow wounds produced by deroofing and } \\
\text { in larger surgical defects, resulting from wide } \\
\text { excision. SIH of large wounds has many } \\
\text { advantages, including scars that have } \\
\text { considerably smaller dimensions in } \\
\text { comparison with the initial defect, lack of } \\
\text { donor sites, no flap or graft loss and an } \\
\text { acceptable range of motion. Disadvantages } \\
\text { include the relatively long healing times, } \\
\text { painful dressing changes, need for meticulous } \\
\text { wound care, and risk of wound contracture, } \\
\text { particularly with large excisions. }\end{array}$ \\
\hline Primary suture & $\begin{array}{l}\text { Primary suture is mostly done in the "mild" } \\
\text { variety of the disease and it is appropriate } \\
\text { only in case of minor defects surrounded by } \\
\text { lax skin. }\end{array}$ \\
\hline $\begin{array}{r}\text { Artificial dermis } \\
\text { and skin graft }\end{array}$ & $\begin{array}{l}\text { Excision and split-thickness skin graft (STSG) } \\
\text { remains the most versatile procedure of } \\
\text { choice to close large areas of resection and } \\
\text { the result of this procedure is often } \\
\text { satisfactory. In general, skin grafts may be } \\
\text { complicated by graft healing problems and } \\
\text { donor-site morbidity and may result in } \\
\text { contractures, noticeable differences of color } \\
\text { and texture with the surrounding skin and } \\
\text { extensive scarring. Nevertheless, they ensure } \\
\text { acceptable functional and aesthetic results, } \\
\text { especially in the armpits and buttocks. Recent } \\
\text { data shows that the graft of dermal } \\
\text { substitutes, using a two-step procedure, can } \\
\text { be used for the treatment of severe } \\
\text { hidradenitis suppurativa (HS) with good } \\
\text { aesthetic and functional results. }\end{array}$ \\
\hline Flaps & $\begin{array}{l}\text { Flaps ensure the best quality of skin closure and } \\
\text { may prevent contractures and bad scarring. } \\
\text { Some disadvantages can be identified with } \\
\text { respect to skin grafts: The harvesting } \\
\text { procedure is more difficult and invasive, in } \\
\text { addition flaps are more prone to serious } \\
\text { complications like tissue necrosis and } \\
\text { hemorrhage. Moreover, local flaps might } \\
\text { sometimes carry the same affected skin and } \\
\text { lead to local recurrences. Therefore, local or } \\
\text { regional flaps can only be used if a wide and } \\
\text { adequate excision with safe margins is } \\
\text { performed. }\end{array}$ \\
\hline \multicolumn{2}{|c|}{ Postsurgical wound care } \\
\hline $\mathrm{SIH}$ & $\begin{array}{l}\text { The goal of postoperative care in large wounds } \\
\text { left for SIH is to maintain a moist and clean } \\
\text { wound, achieved with wound dressing } \\
\text { changes, hydrotherapy and physical therapy. } \\
\text { The daily use antiseptic medications are } \\
\text { essential in order to avoid severe infection } \\
\text { and postoperative complications. }\end{array}$ \\
\hline
\end{tabular}

(Continues)
TABLE 1 (Continued)

$\begin{aligned} & \text { Postsurgical wound care } \\ & \begin{array}{l}\text { Primary suture } \\ \text { and flap }\end{array} \\ & \text { Local wound care is decisive to heal } \\ & \text { postsurgical skin defects in patients with HS. } \\ & \text { The positioning of drainage and the } \\ & \text { administration of antibiotics are crucial to } \\ & \text { prevent complications in postsurgical } \\ & \text { management of flaps. } \\ & \text { Artificial dermis } \\ & \text { and skin graft }\end{aligned} \quad \begin{aligned} & \text { STSG and artificial dermis can be applied } \\ & \text { immediately after skin or artificial dermis } \\ & \text { grafting to secure the graft firmly to the } \\ & \text { wound bed. }\end{aligned}$

Patients with chronic and extensive Hurley stage III disease, may be managed by local or wide excision. In wide excision, an area embracing all lesions is removed with surgical margins designed to reach beyond the clinical borders of disease activity and with complete surgical resection of apocrine glands.

Wide surgical excisions must be carried out with wide lateral margins. The deep margin includes the skin, its appendages, and the subcutaneous tissue that should be removed only until normal-appearing fat remains. The muscular fascia must be reached only in the most severe forms of the disease. Therefore, wide excision should not always be as destructive as the "en bloc deep to the fascia" technique used in managing malignancy. It is advised to adjust the excision to the extent and severity of the disease, as well as to the dynamics of its development (Garbarino et al., 2019).

\section{3 | RECONSTRUCTIVE TECHNIQUES}

Multiple reconstructive modalities after surgical excision have been described including primary closure, healing by secondary intent, splitthickness skin graft and flap closure (Alikhan et al., 2019b; Garbarino et al., 2019). Despite this variability, there is no general consensus on the preferred surgical technique (Table 1).

\section{4 | CONCLUSION}

Our letter focuses on the complex issue of the surgical and postsurgical management of HS patients. At present, only few cohort studies and case series, with low-grade evidence, are available regarding surgical therapies in HS. The best combinations of therapies, including antibiotics and immunomodulatory therapies, for the phases which occur before, during and after surgery, are still poorly defined (Alikhan et al., 2019b). In addition to the surgical and reconstructive techniques, HS surgical treatment should embrace the postsurgical wound care before and after surgery, in order to decrease the time of hospital stay and to achieve the best functional and aesthetic results. Future studies on large series of patients will define the best management of 
HS patients that undergo surgical treatment providing practical suggestions on when and how treatments should be used in order to improve surgical efficacy and decrease the risk of complications.

\section{CONFLICT OF INTEREST}

The authors declare no potential conflict of interest.

\section{ORCID}

Marco Manfredini (D) https://orcid.org/0000-0003-3601-655X

Federico Garbarino (D) https://orcid.org/0000-0002-3958-5718

\section{REFERENCES}

Alikhan, A., Sayed, C., Alavi, A., Alhusayen, R., Brassard, A., Burkhart, C., ... Poulin, Y. (2019a). North American clinical management guidelines for hidradenitis suppurativa: A publication from the United States and Canadian Hidradenitis Suppurativa Foundations: Part I: Diagnosis, evaluation, and the use of complementary and procedural management. Journal of the American Academy of Dermatology, 81(1), 76-90. https://doi.org/10.1016/j.jaad.2019.02.067

Alikhan, A., Sayed, C., Alavi, A., Alhusayen, R., Brassard, A., Burkhart, C., ... Poulin, Y. (2019b). North American clinical management guidelines for hidradenitis suppurativa: A publication from the United States and Canadian Hidradenitis Suppurativa Foundations: Part II: Topical, intralesional, and systemic medical management. Journal of the American Academy of Dermatology, 81(1), 91-101. https://doi.org/10.1016/ j.jaad.2019.02.068

Bettoli, V., Manfredini, M., Calamo, G., Forconi, R., Bencivelli, D., Mantovani, L., ... Corazza, M. (2018). Long-term adalimumab treatment of hidradenitis suppurativa: Results and practical insights from a reallife experience. Dermatologic Therapy, 31(6), e12737. https://doi.org/ 10.1111/dth.12737

Bettoli, V., Manfredini, M., Massoli, L., Carillo, C., Barozzi, A., Amendolagine, G., ... Corazza, M. (2018). Rates of antibiotic resistance/sensitivity in bacterial cultures of hidradenitis suppurativa patients. Journal of the European Academy of Dermatology and Venereology, 33(5), 930-936.

Garbarino, F., Manfredini, M., Rossi, E., \& Magnoni, C. (2019). Two-step surgery in extensive anogenital hidradenitis: What kind of faecal management? International Wound Journal, 16(3), 866-867. https://doi. org/10.1111/iwj.13102

How to cite this article: Manfredini M, Garbarino F, Bigi L, Pellacani G, Magnoni C. Surgical and postsurgical wound care in hidradenitis suppurativa. Dermatologic Therapy. 2020;33: e13282. https://doi.org/10.1111/dth.13282 